\title{
Supplementary High-Input Impedance Voltage-Mode Universal Biquadratic Filter Using DVCCs
}

\author{
Jitendra Mohan $^{1}$ and Sudhanshu Maheshwari² \\ ${ }^{1}$ Department of Electronics and Communications, Jaypee Institute of Information Technology, \\ Noida 201304, India \\ ${ }^{2}$ Department of Electronics Engineering, Z. H. College of Engineering and Technology, Aligarh Muslim University, \\ Aligarh 202002, India \\ Correspondence should be addressed to Jitendra Mohan, jitendramv2000@rediffmail.com \\ Received 9 April 2012; Accepted 12 July 2012 \\ Academic Editor: Andrzej Dzielinski
}

Copyright (C 2012 J. Mohan and S. Maheshwari. This is an open access article distributed under the Creative Commons Attribution License, which permits unrestricted use, distribution, and reproduction in any medium, provided the original work is properly cited.

To further extend the existing knowledge on voltage-mode universal biquadratic filter, in this paper, a new biquadratic filter circuit with single input and multiple outputs is proposed, employing three differential voltage current conveyors (DVCCs), three resistors, and two grounded capacitors. The proposed circuit realizes all the standard filter functions, that is, high-pass, band-pass, low-pass, notch, and all-pass filters simultaneously. The circuit enjoys the feature of high-input impedance, orthogonal control of resonance angular frequency $\left(\omega_{\mathrm{o}}\right)$, and quality factor $(Q)$ via grounded resistor and the use of grounded capacitors which is ideal for IC implementation.

\section{Introduction}

Analog filters are the basic building blocks and widely used for continuous-time signal processing. Application of analog filters employing current-mode active elements extends over a large number of fields [1]. The filter circuits may be used in phase-locked loop frequency modulation stereo demodulators, touch-tone telephone tone decoder, and cross-over networks in a three-way high fidelity loudspeaker $[2,3]$. In the literature several voltage-mode biquadratic filters are presented which uses different types of current conveyors [4-28]. The voltage-mode filters with high-input impedance are of great interest because they can be easily cascaded to synthesize higher-order filters $[7,10,13,17,26$, $28]$. In the literature there are a number of voltage-mode universal biquadratic filters with single-input multipleoutputs (SIMO) $[4-12,18]$ that are available. However, these reported circuits suffer from one or more of the following drawbacks:

(i) excessive use of passive components $[4,6,7]$;

(ii) low-input impedance $[5,6,8,9,11,18]$; (iii) lack of orthogonal control over the resonance angular frequency $\left(\omega_{0}\right)$ and quality factor $(Q)[10,12]$.

In this paper, a new voltage-mode universal biquadratic filter using three differential voltage current conveyors [29], two grounded capacitors, and three resistors is presented. The circuit realizes the entire standard filter functions, that is, high pass (HP), band pass (BP), low pass (LP), notch $(\mathrm{NH})$, and all pass (AP) from the same circuit configuration. The circuit also possesses high-input impedance and provides orthogonal control of the $\omega_{o}$ and $Q$ via grounded resistor.

\section{Differential Voltage Current Conveyor (DVCC)}

The DVCC is first introduced long back as a modified current conveyor by Pal [30] and developed by Elwan and Soliman in 1997 [29]. It is a versatile building block, especially designed to handle differential and floating input signals [30, 31]. Using standard notation, the terminal relations of a DVCC 


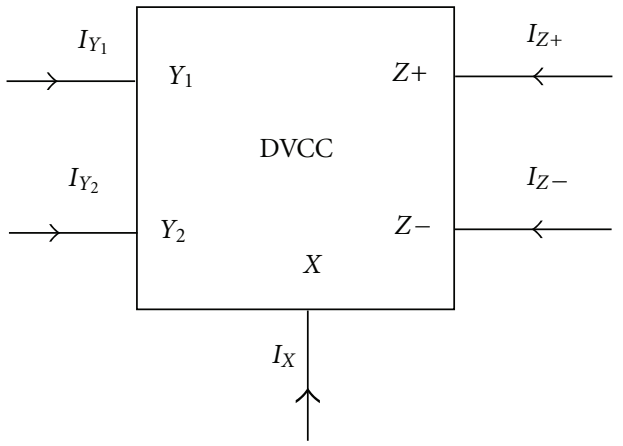

(a)

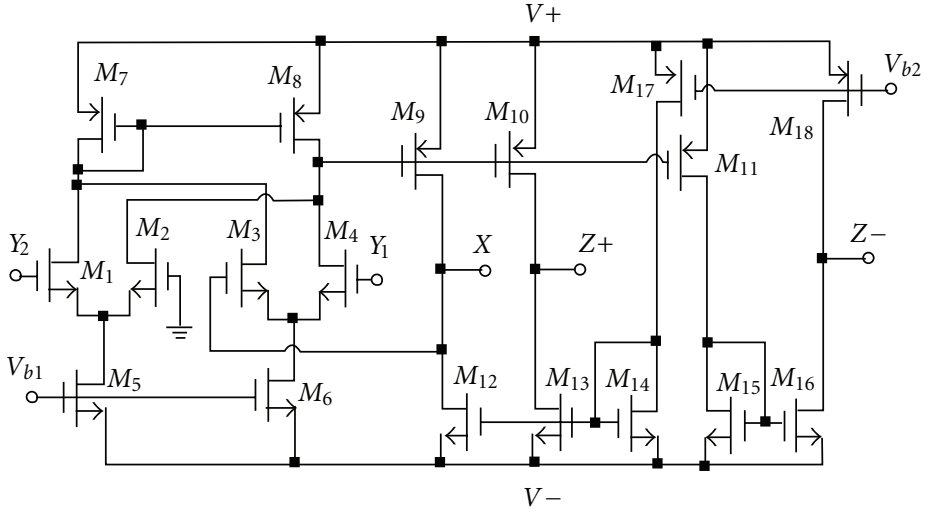

(b)

Figure 1: (a) Symbol of DVCC. (b) CMOS implementation of DVCC.

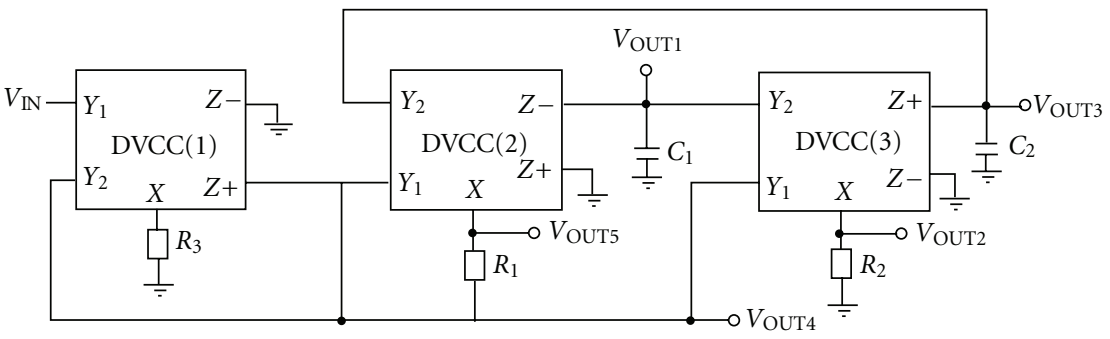

FIgURE 2: Voltage-mode universal biquadratic filter.

are shown in Figure 1 and described by the following matrix equation:

$$
\left[\begin{array}{c}
I_{Y_{1}} \\
I_{Y_{2}} \\
V_{X} \\
I_{Z+} \\
I_{Z-}
\end{array}\right]=\left[\begin{array}{ccccc}
0 & 0 & 0 & 0 & 0 \\
0 & 0 & 0 & 0 & 0 \\
1 & -1 & 0 & 0 & 0 \\
0 & 0 & 1 & 0 & 0 \\
0 & 0 & -1 & 0 & 0
\end{array}\right]\left[\begin{array}{c}
V_{Y_{1}} \\
V_{Y_{2}} \\
I_{X} \\
V_{Z+} \\
V_{Z-}
\end{array}\right] .
$$

The difference of the $Y_{1}$ and $Y_{2}$ terminal voltages is conveyed to the $X$ terminal; the current input at the $X$ terminal is conveyed to the $Z+$, with the same polarity and $Z$ - terminal with inverse polarity. The DVCC is characterized by highinput impedance at the $Y_{1}$ and $Y_{2}$ terminals, high-output impedance at the $Z+$ and $Z$ - terminals, and low impedance at the $X$ terminal.

\section{Proposed Circuit}

The proposed voltage-mode universal biquadratic filter is shown in Figure 2, employing three DVCCs, three resistors, and two grounded capacitors. The routine analysis of the proposed circuit in Figure 2 using (1) yields the filter transfer functions as

$$
\begin{aligned}
\frac{V_{\text {OUT1 }}}{V_{\mathrm{IN}}} & =\frac{1}{s^{2} C_{1} C_{2} R_{1} R_{2}+s C_{1} R_{3}+1} \\
\frac{V_{\text {OUT2 }}}{V_{\mathrm{IN}}} & =\frac{s^{2} C_{1} C_{2} R_{1} R_{2}}{s^{2} C_{1} C_{2} R_{1} R_{2}+s C_{1} R_{3}+1} \\
\frac{V_{\text {OUT3 }}}{V_{\mathrm{IN}}} & =\frac{s C_{1} R_{1}}{s^{2} C_{1} C_{2} R_{1} R_{2}+s C_{1} R_{3}+1} \\
\frac{V_{\text {OUT4 }}}{V_{\mathrm{IN}}} & =\frac{s^{2} C_{1} C_{2} R_{1} R_{2}+1}{s^{2} C_{1} C_{2} R_{1} R_{2}+s C_{1} R_{3}+1} \\
\frac{V_{\text {OUT5 }}}{V_{\mathrm{IN}}} & =\frac{s^{2} C_{1} C_{2} R_{1} R_{2}-s C_{1} R_{1}+1}{s^{2} C_{1} C_{2} R_{1} R_{2}+s C_{1} R_{3}+1} .
\end{aligned}
$$

It can be seen from (2) that an LP response is obtained from $V_{\text {OUT1 }}$; HP response is obtained from $V_{\text {OUT2 }}$; BP response is obtained from $V_{\text {OUT3 }}$; $\mathrm{NH}$ response is obtained from $V_{\text {OUT4 }}$; if $R_{3}=R_{1}$, AP response is obtained from $V_{\text {OUT5 }}$. In all the cases, the parameters $\omega_{o}$ and $Q$ of the filter can be found as

$$
\begin{gathered}
\omega_{\mathrm{o}}=\left(\frac{1}{C_{1} C_{2} R_{1} R_{2}}\right)^{1 / 2}, \\
Q=\frac{1}{R_{3}} \sqrt{\frac{R_{1} R_{2} C_{2}}{C_{1}}} .
\end{gathered}
$$


TABLE 1: TSMC $0.35 \mu \mathrm{m}$ CMOS process parameters.

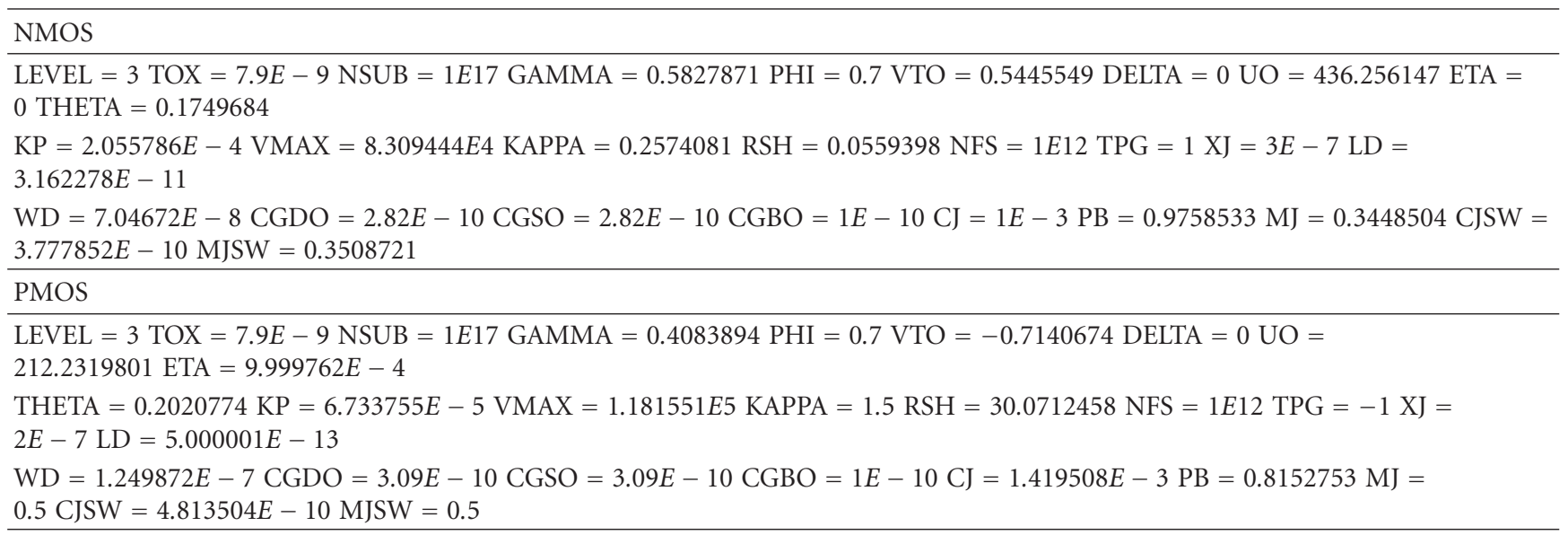

From (3), the $Q$ of the proposed filter can be controlled independently of $\omega_{0}$ by varying $R_{3}$. Since the input voltage signal is connected directly to the $Y_{1}$ port of the DVCC (1) and the input current to the $Y_{1}$ port is zero $\left(I_{Y_{1}}=0\right)$, the circuit has the feature of high-input impedance. Thus the proposed circuit is capable to realize all five standard filter functions simultaneously and without changing the circuit topology, unlike the previously proposed circuit in [26]. The circuit reported in [26] uses two floating resistors but the proposed circuit employs only one floating resistor. The circuit needs no component-matching conditions except for the all-pass filter realization.

Note that the proposed circuit uses two grounded capacitors at the $Z$-terminal and three resistors at the $X$ terminal of the DVCCs. The design offers the feature of a direct incorporation of the shunt parasitic capacitances at the $Z$-terminals and the series parasitic resistances at the $X$ terminal, as a part of the main capacitors $\left(C_{1}\right.$ and $\left.C_{2}\right)$ and resistors $\left(R_{1}, R_{2}\right.$, and $\left.R_{3}\right)$.

\section{Nonideal Analysis}

Taking the nonidealities of the DVCC into account, the relationship of the terminal voltages and currents of the DVCC can be rewritten as

$$
\left[\begin{array}{c}
I_{Y_{1}} \\
I_{Y_{2}} \\
V_{X} \\
I_{Z+} \\
I_{Z-}
\end{array}\right]=\left[\begin{array}{ccccc}
0 & 0 & 0 & 0 & 0 \\
0 & 0 & 0 & 0 & 0 \\
\beta_{k 1} & -\beta_{k 2} & 0 & 0 & 0 \\
0 & 0 & \alpha_{k 1} & 0 & 0 \\
0 & 0 & -\alpha_{k 2} & 0 & 0
\end{array}\right]\left[\begin{array}{c}
V_{Y_{1}} \\
V_{Y_{2}} \\
I_{X} \\
V_{Z+} \\
V_{Z-}
\end{array}\right],
$$

where $\beta_{k 1}(s), \beta_{k 2}(s)$ represent the frequency transfers of the internal voltage followers and $\alpha_{k 1}(s), \alpha_{k 2}(s)$ represent the frequency transfers of the internal current followers of the $k$ th-DVCC, respectively. They can be approximated by firstorder low-pass functions, which can be considered to have a unity value for frequencies [30]. If this circuit is working at frequencies much less than the corner frequencies of $\beta_{k 1}(s)$, $\beta_{k 2}(s), \alpha_{k 1}(s)$, and, $\alpha_{k 2}(s)$, namely, then $\beta_{k 1}(s)=\beta_{k 1}=1-\varepsilon_{k v 1}$

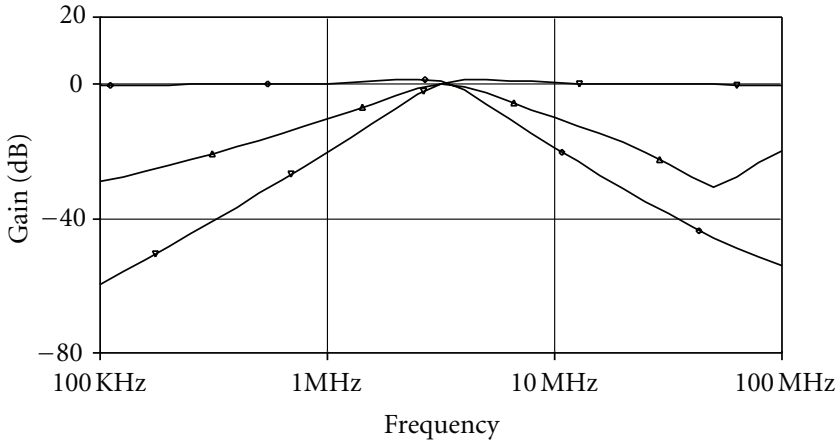

$\diamond \mathrm{DB}(V(3))$

$\nabla \mathrm{DB}(V(5))$

$\triangle \mathrm{DB}(V(6))$

Figure 3: Gain plots of LP, HP, and BP filters for $Q=1$ at $3.18 \mathrm{MHz}$.

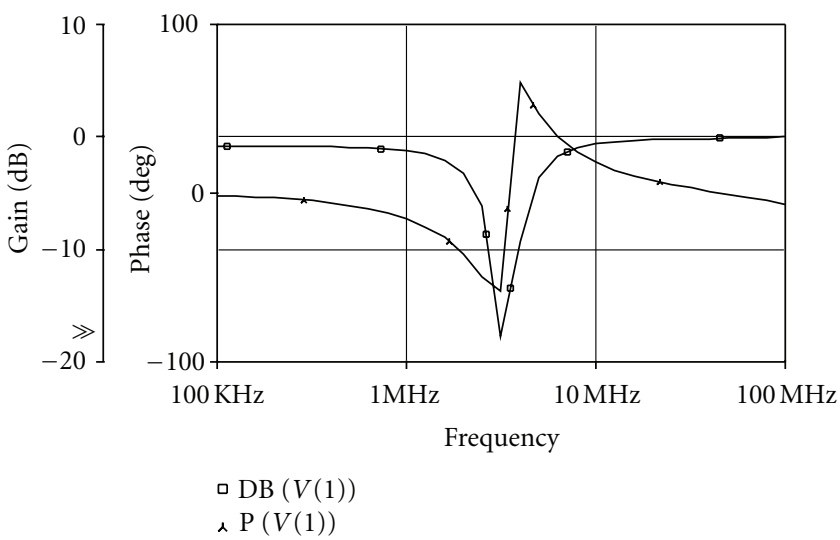

FIGURE 4: Gain and phase plots of NH filter for $Q=1$ at $3.18 \mathrm{MHz}$.

and $\varepsilon_{k v 1}\left(\left|\varepsilon_{k v 1} \ll 1\right|\right)$ denotes the voltage tracking error from the $Y_{1}$ terminal to the $X$ terminal of the $k$ th-DVCC; $\beta_{k 2}(s)=$ $\beta_{k 2}=1-\varepsilon_{k v 2}$ and $\varepsilon_{k v 2}\left(\left|\varepsilon_{k v 2} \ll 1\right|\right)$ denotes the voltage tracking error from the $Y_{2}$ terminal to the $X$ terminal of the 


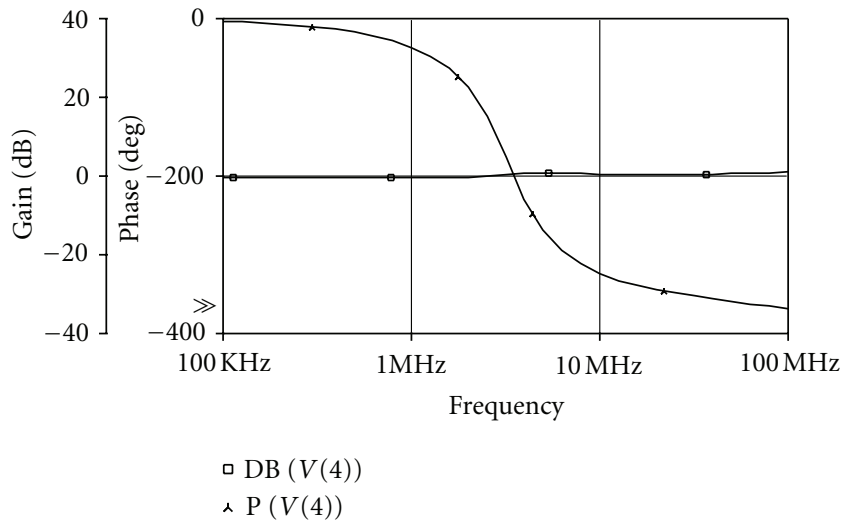

Figure 5: Gain and phase plots of AP filter for $Q=1$ at $3.18 \mathrm{MHz}$.

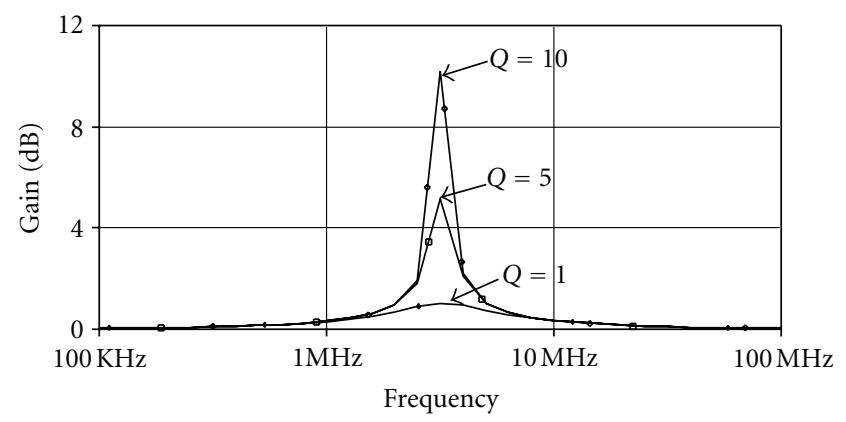

* $V(2) / V(7)$

- $V(2) / V(7)$

- $V(2) / V(7)$

Figure 6: $Q$ tuning $(Q=1,5$, and 10$)$ of $\mathrm{BP}$ filter at $3.18 \mathrm{MHz}$.

$k$ th-DVCC, $\alpha_{k 1}(s)=\alpha_{k 1}=1-\varepsilon_{k i 1}$, and $\varepsilon_{k i 1}\left(\left|\varepsilon_{k i 1} \ll 1\right|\right)$ denotes the current tracking error from the $X$ terminal to the $Z+$ terminal; $\alpha_{k 2}(s)=\alpha_{k 2}=1-\varepsilon_{k i 2}$ and $\varepsilon_{k i 2}\left(\left|\varepsilon_{k i 2} \ll 1\right|\right)$ denotes the current tracking error from the $X$ terminal to the $Z$ - terminal of the $k$ th-DVCC.

Taking the tracking errors of the nonideal DVCC into account, the denominator of (2) becomes

$$
\begin{aligned}
D(s)= & s_{2} C_{1} C_{2} R_{2} \alpha_{22}\left(R_{3} \alpha_{11}+R_{1} \beta_{12}-R_{3} \alpha_{11} \beta_{21}\right) \\
& +s C_{1} R_{3} \beta_{22} \beta_{31} \alpha_{11} \alpha_{22}+\beta_{12} \beta_{22} \beta_{32} .
\end{aligned}
$$

The parameters $\omega_{o}$ and $Q$ from (5) can be rewritten as

$$
\begin{gathered}
\omega_{o}=\left(\frac{\beta_{12} \beta_{22} \beta_{32}}{C_{1} C_{2} R_{2} \alpha_{22}\left(R_{3} \alpha_{11}+R_{1} \beta_{12}-R_{3} \alpha_{11} \beta_{21}\right)}\right)^{1 / 2}, \\
Q=\frac{1}{R_{3} \beta_{31} \alpha_{11}}\left(\frac{C_{2} R_{2} \beta_{12} \beta_{32}\left(R_{3} \alpha_{11}+R_{1} \beta_{12}-R_{3} \alpha_{11} \beta_{21}\right)}{C_{1} \beta_{22} \alpha_{22}}\right)^{1 / 2} .
\end{gathered}
$$

The active and passive sensitivities of the proposed SIMO voltage-mode filter are derived from (6). These are as follows:

$$
\begin{gathered}
S_{C_{1}, C_{2}, R_{2}}^{\omega_{o}}=-\frac{1}{2}, \\
S_{R_{1}}^{\omega_{o}}=-\frac{1}{2} \frac{R_{1} \beta_{12}}{\left(R_{3} \alpha_{11}+R_{1} \beta_{12}-R_{3} \alpha_{11} \beta_{21}\right)}, \\
S_{\beta_{22}, \beta_{32}}^{\omega_{o}}=-S_{\alpha_{22}}^{\omega_{o}}=\frac{1}{2}, \\
S_{\beta_{12}}^{\omega_{o}}=\frac{1}{2} \frac{\left(R_{3} \alpha_{11}-R_{3} \alpha_{11} \beta_{21}\right)}{\left(R_{3} \alpha_{11}+R_{1} \beta_{12}-R_{3} \alpha_{11} \beta_{21}\right)}, \\
S_{R_{3}, \alpha_{11}}^{\omega_{o}}=-\frac{1}{2} \frac{R_{3} \alpha_{11}\left(1-\beta_{21}\right)}{\left(R_{3} \alpha_{11}+R_{1} \beta_{12}-R_{3} \alpha_{11} \beta_{21}\right)}, \\
S_{\beta_{21}}^{\omega_{o}}=\frac{1}{2} \frac{R_{3} \alpha_{11} \beta_{21}}{\left(R_{3} \alpha_{11}+R_{1} \beta_{12}-R_{3} \alpha_{11} \beta_{21}\right)}, \\
S_{R_{1}}^{Q}=-\frac{1}{2} \frac{S_{C_{1}}^{Q}=\frac{1}{2}, \quad S_{\beta_{32}}^{Q}=-S_{\beta_{22}, \alpha_{22}}^{Q}=\frac{1}{2},}{\left(R_{3} \alpha_{11}\left(1-\beta_{21}\right)+R_{1} \beta_{12}\right)}, \\
S_{R_{3}, \alpha_{11}}^{Q}=\frac{\left(-2 R_{1} \beta_{12}-R_{3} \alpha_{11}\left(1-\beta_{21}\right)\right)}{2\left(R_{3} \alpha_{11}\left(1-\beta_{21}\right)+R_{1} \beta_{12}\right)}, \\
S_{\beta_{12}}^{Q}=\frac{1}{2} \frac{S_{\beta_{31}}^{Q}=-1,}{\left(R_{3} \alpha_{11}+2 R_{1} \beta_{12}-R_{3} \alpha_{11} \beta_{21}\right)}, \\
\left(R_{3} \alpha_{11}+R_{1} \beta_{12}-R_{3} \alpha_{11} \beta_{21}\right) \\
\frac{R_{3} \alpha_{11} \beta_{21}}{\left(R_{3} \alpha_{11}\left(1-\beta_{21}\right)+R_{1} \beta_{12}\right)} .
\end{gathered}
$$

From the results it is evident that the sensitivities are low and within unity in absolute value. Thus the proposed circuit can be classified as insensitive as all the active and passive sensitivities are less than or equal to unity [28].

\section{Simulation Results}

The performance of the proposed voltage-mode universal biquadratic filter in Figure 2 is verified using the PSPICE simulation program. The MOS transistors are simulated using $0.35 \mu \mathrm{m}$ CMOS process parameters given in Table 1 . The aspect ratios of the transistors used in the simulation are given in Table 2 . The supply voltages and biasing voltage are given by $V+=2 \mathrm{~V}, V-=-1.9 \mathrm{~V}, V_{b 1}=-1.23 \mathrm{~V}$, and $V_{b 2}=-1.15 \mathrm{~V}$, respectively. The proposed circuit is designed for $3.18 \mathrm{MHz}$ and $Q=1$ by choosing $R_{1}=R_{2}=R_{3}=5 \mathrm{k} \Omega$ and $C_{1}=C_{2}=10 \mathrm{pF}$. Figure 3 shows the simulated gain responses for the LP, HP, and BP filters and agrees well with the designed values. Figures 4 and 5 show the simulated gain and phase responses for the NH and AP filters. Next, $Q$ tuning of BP filter at constant frequency of $3.18 \mathrm{MHz}$ is shown in Figure 6. The circuit of Figure 2 is designed for $Q$ values of 1,5 , and 10 with $R_{3}$ values as $5 \mathrm{k} \Omega, 1 \mathrm{k} \Omega$, and $500 \Omega$, respectively, with $C_{1}=C_{2}=10 \mathrm{pF}$ and $R_{1}=R_{2}=5 \mathrm{k} \Omega$. 


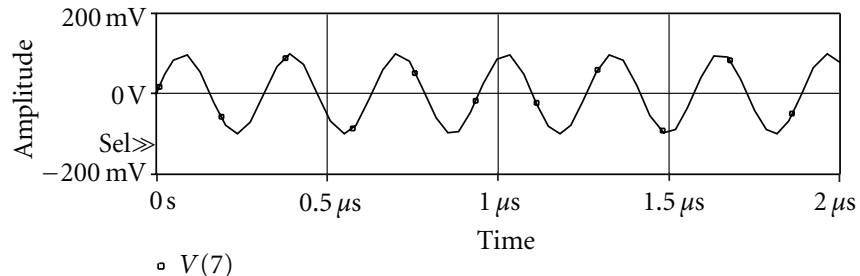

(a)

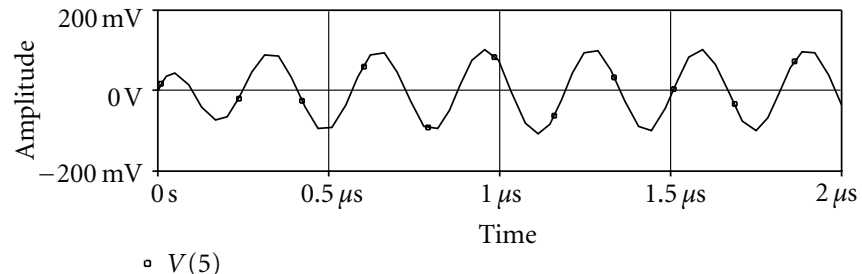

(b)

FIgURE 7: Input (a) and HP output (b) signal waveforms to demonstrate the ac dynamic range at $V_{\text {OUT2 }}$.

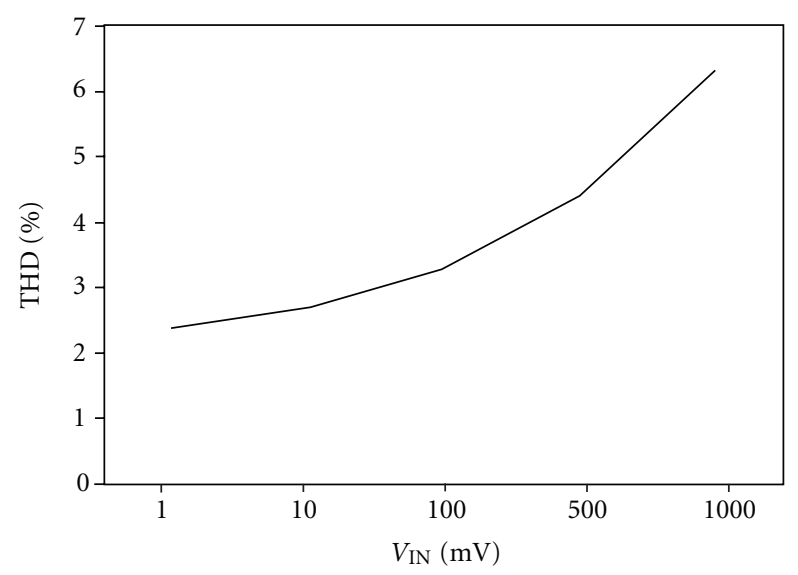

FIgURE 8: THD variation with $V_{\text {IN }}$ for HP filter at $V_{\text {OUT2 }}$.

TABle 2: Aspect ratios of the MOS in Figure 1.

\begin{tabular}{lcc}
\hline MOS transistors & $W(\mu \mathrm{m})$ & $L(\mu \mathrm{m})$ \\
\hline $\mathrm{M}_{1}-\mathrm{M}_{4}$ & 1.2 & 0.8 \\
$\mathrm{M}_{7}, \mathrm{M}_{8}$ & 6.6 & 0.8 \\
$\mathrm{M}_{9}-\mathrm{M}_{11}, \mathrm{M}_{17}-\mathrm{M}_{18}$ & 18.6 & 0.6 \\
$\mathrm{M}_{5}, \mathrm{M}_{6}, \mathrm{M}_{12}-\mathrm{M}_{16}$ & 24 & 0.8 \\
\hline
\end{tabular}

To test the input dynamic range of the proposed filter, the simulation of the HP filter as example has been repeated for a sinusoidal input signal at $3.18 \mathrm{MHz}$. Figure 7 shows the input dynamic range of the HP filter which extends upto amplitude $200 \mathrm{mV}$ (peak to peak) without significant distortion. In Figure 8 , the total harmonic distortion (THD) of the $V_{\text {OUT2 }}$ output voltage is given at $3.18 \mathrm{MHz}$ operation frequency. Figure 9 shows the INOISE and ONOISE simulated amplitudefrequency responses of the proposed LP filter at $V_{\text {OUT1 }}$.

\section{Conclusion}

The voltage-mode universal biquadratic filter realizes all the standard filter functions by employing three DVCCs and five passive components. It offers high-input impedance, which permit the use of circuits in cascade without requiring any impedance-matching device. Moreover, the proposed circuit enjoys the following features: orthogonal control of $\omega_{o}$ and $Q$, low active and passive sensitivity, and the direct incorporation of parasitic resistance and parasitic capacitance at

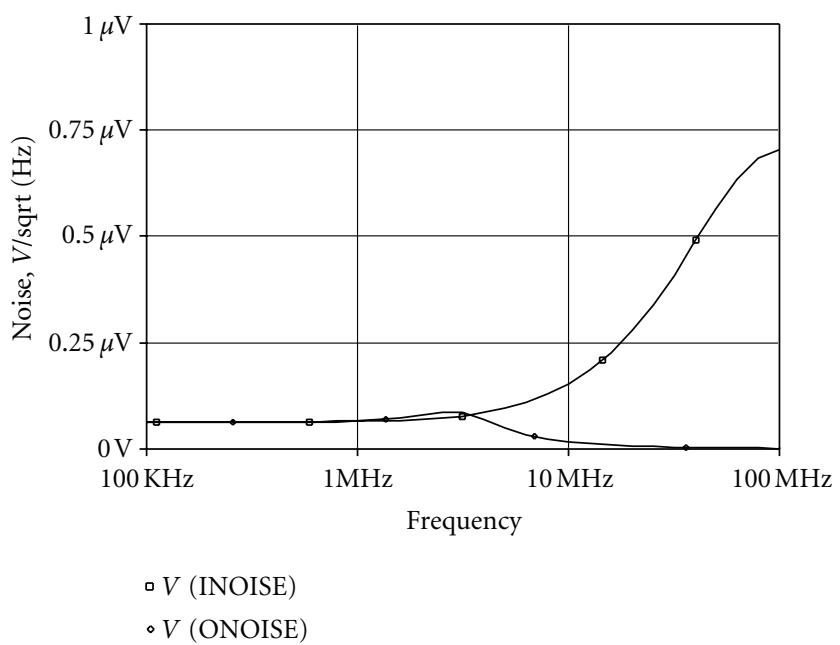

FIGURE 9: The input and output referred noise spectral densities of the proposed LP filter at $V_{\text {OUT1 }}$.

the $X$-terminal and $Z$-terminal of the respective DVCCs, as a part of main resistor and capacitor. So, the new circuit will enhance the existing knowledge on the voltage-mode universal biquadratic filter. PSPICE simulations with TSMC $0.35 \mu \mathrm{m}$ process confirm the theoretical prediction.

\section{References}

[1] B. Wilson, "Recent developments in current conveyors and current-mode circuits," IEE proceedings G, vol. 137, no. 2, pp. 63-77, 1990.

[2] A. Fabre, O. Saaid, F. Wiest, and C. Boucheron, "Low power current-mode second-order bandpass if filter," IEEE Transactions on Circuits and Systems II, vol. 44, no. 6, pp. 436446, 1997.

[3] M. A. Ibrahim, S. Minaei, and H. Kuntman, "A $22.5 \mathrm{MHz}$ current-mode KHN-biquad using differential voltage current conveyor and grounded passive elements," International Journal of Electronics and Communications, vol. 59, no. 5, pp. 311318, 2005.

[4] M. T. Abuelma'atti and H. A. Al-Zaher, "New universal filter with one input and five outputs using current-feedback amplifiers," Analog Integrated Circuits and Signal Processing, vol. 16, no. 3, pp. 239-244, 1998.

[5] H. P. Chen and S. S. Shen, "A versatile universal capacitorgrounded voltage-mode filter using DVCCs," ETRI Journal, vol. 29, no. 4, pp. 470-476, 2007. 
[6] J. W. Horng, C. L. Hou, C. M. Chang, W. Y. Chung, and H. Y. Wei, "Voltage-mode universal biquadratic filters with one input and five outputs using MOCCIIs," Computers and Electrical Engineering, vol. 31, no. 3, pp. 190-202, 2005.

[7] J. W. Horng, C. L. Hou, C. M. Chang, H. P. Chou, and C. T. Lin, "High input impedance voltage-mode universal biquadratic filter with one input and five outputs using current conveyors," Circuits, Systems, and Signal Processing, vol. 25, no. 6, pp. 767-777, 2006.

[8] H. P. Chen, "Universal voltage-mode filter using only plustype DDCCs," Analog Integrated Circuits and Signal Processing, vol. 50, no. 2, pp. 137-139, 2007.

[9] H. P. Chen, "Single FDCCII-based universal voltage-mode filter," International Journal of Electronics and Communications, vol. 63, no. 9, pp. 713-719, 2009.

[10] H. P. Chen, "Voltage-mode FDCCII-based universal filters," International Journal of Electronics and Communications, vol. 62, no. 4, pp. 320-323, 2008.

[11] J. W. Horng, "Lossless inductance simulation and voltagemode universal biquadratic filter with one input and five outputs using DVCCs," Analog Integrated Circuits and Signal Processing, vol. 62, no. 3, pp. 407-413, 2010.

[12] S. Minaei and E. Yuce, "All-grounded passive elements voltagemode DVCC-based universal filters," Circuits, Systems, and Signal Processing, vol. 29, no. 2, pp. 295-309, 2010.

[13] M. Higashimura and Y. Fukui, "Realization of all-pass and notch filters using a single current conveyor," International Journal of Electronics, vol. 65, no. 4, pp. 823-828, 1988.

[14] B. Metin, S. Minaei, and O. Cicekoglu, "Enhanced dynamic range analog filter topologies with a notch/all-pass circuit example," Analog Integrated Circuits and Signal Processing, vol. 51, no. 3, pp. 181-189, 2007.

[15] M. A. Ibrahim, S. Minaei, and H. Kuntman, "DVCC based differential-mode all-pass and notch filters with high CMRR," International Journal of Electronics, vol. 93, no. 4, pp. 231-240, 2006.

[16] S. Minaei, I. C. Göknar, and O. Cicekoglu, "A new differential configuration suitable for realization of high CMRR, allpass/notch filters," Electrical Engineering, vol. 88, no. 4, pp. 317-326, 2006.

[17] N. A. Shah and M. A. Malik, "High input impedance HP, BP and LP filters using FTFNs," Indian Journal of Pure and Applied Physics, vol. 41, no. 12, pp. 967-969, 2003.

[18] N. A. Shah, S. Z. Iqbal, and M. F. Rather, "Versatile voltagemode CFA-based universal filter," International Journal of Electronics and Communications, vol. 59, no. 3, pp. 192-194, 2005.

[19] M. T. Abuelma'atti, "A novel mixed-mode current-controlled current-conveyor-based filter," Active and Passive Electronic Components, vol. 26, no. 3, pp. 185-191, 2003.

[20] M. T. Abuelma'atti, A. Bentrcia, and S. M. Al-Shahrani, "A novel mixed-mode current-conveyor-based filter," International Journal of Electronics, vol. 91, no. 3, pp. 191-197, 2004.

[21] S. Maheshwari, "High performance voltage-mode multifunction filter with minimum component count," WSEAS Transactions on Electronics, vol. 5, no. 6, pp. 244-249, 2008.

[22] A. M. Soliman, "Kerwin-Huelsman-Newcomb circuit using current conveyors," Electronics Letters, vol. 30, no. 24, pp. 2019-2020, 1994.

[23] A. M. Soliman, "Current conveyors steer universal filter," IEEE Circuits and Devices Magazine, vol. 11, no. 2, pp. 45-46, 1995.

[24] M. Higashimura and Y. Fukui, "Universal filter using plus-type CCIIs," Electronics Letters, vol. 32, no. 9, pp. 810-811, 1996.
[25] A. M. Soliman, "Generation and classification of KerwinHuelsman-Newcomb circuits using the DVCC," International Journal of Circuit Theory and Applications, vol. 37, no. 7, pp. 835-855, 2009.

[26] S. Maheshwari, J. Mohan, and D. S. Chauhan, "High input impedance voltage-mode universal filter and quadrature oscillator," Journal of Circuits, Systems and Computers, vol. 19, no. 7, pp. 1597-1607, 2010.

[27] S. Minaei and M. A. Ibrahim, "A mixed-mode KHN-biquad using DVCC and grounded passive elements suitable for direct cascading," International Journal of Circuit Theory and Applications, vol. 37, no. 7, pp. 793-810, 2009.

[28] A. Fabre, F. Dayoub, L. Duruisseau, and M. Kamoun, "High input impedance insensitive second-order filters implemented from current conveyors," IEEE Transactions on Circuits and Systems I, vol. 41, no. 12, pp. 918-921, 1994.

[29] H. O. Elwan and A. M. Soliman, "Novel CMOS differential voltage current conveyor and its applications," IEE Proceedings $G$, vol. 144, pp. 195-200, 1997.

[30] K. Pal, "Modified current conveyors and their applications," Microelectronics Journal, vol. 20, no. 4, pp. 37-40, 1989.

[31] H. Sedef and C. Acar, "New floating FDNR circuit using differential voltage current conveyors," International Journal of Electronics and Communications, vol. 54, no. 5, pp. 297-301, 2000. 

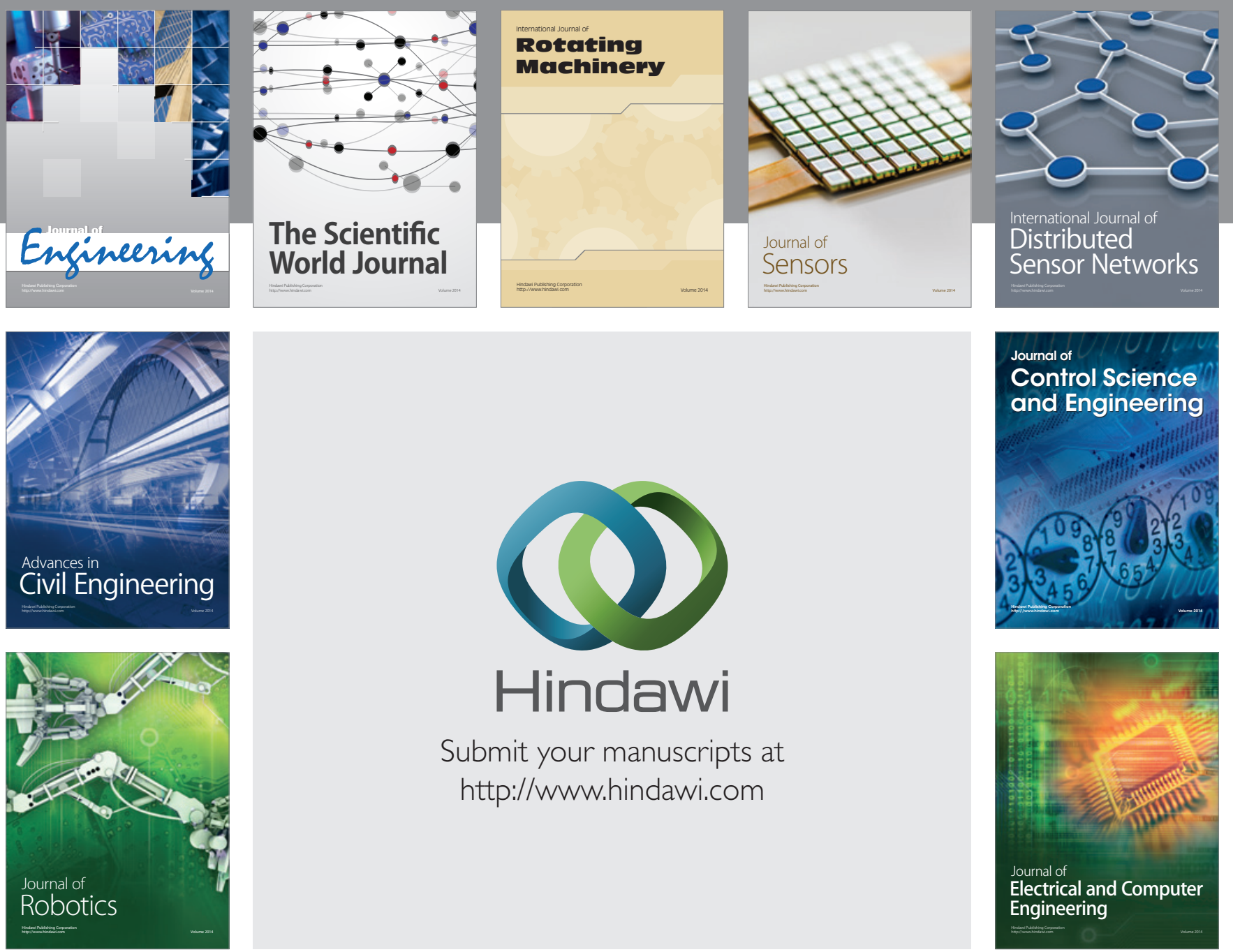

Submit your manuscripts at

http://www.hindawi.com
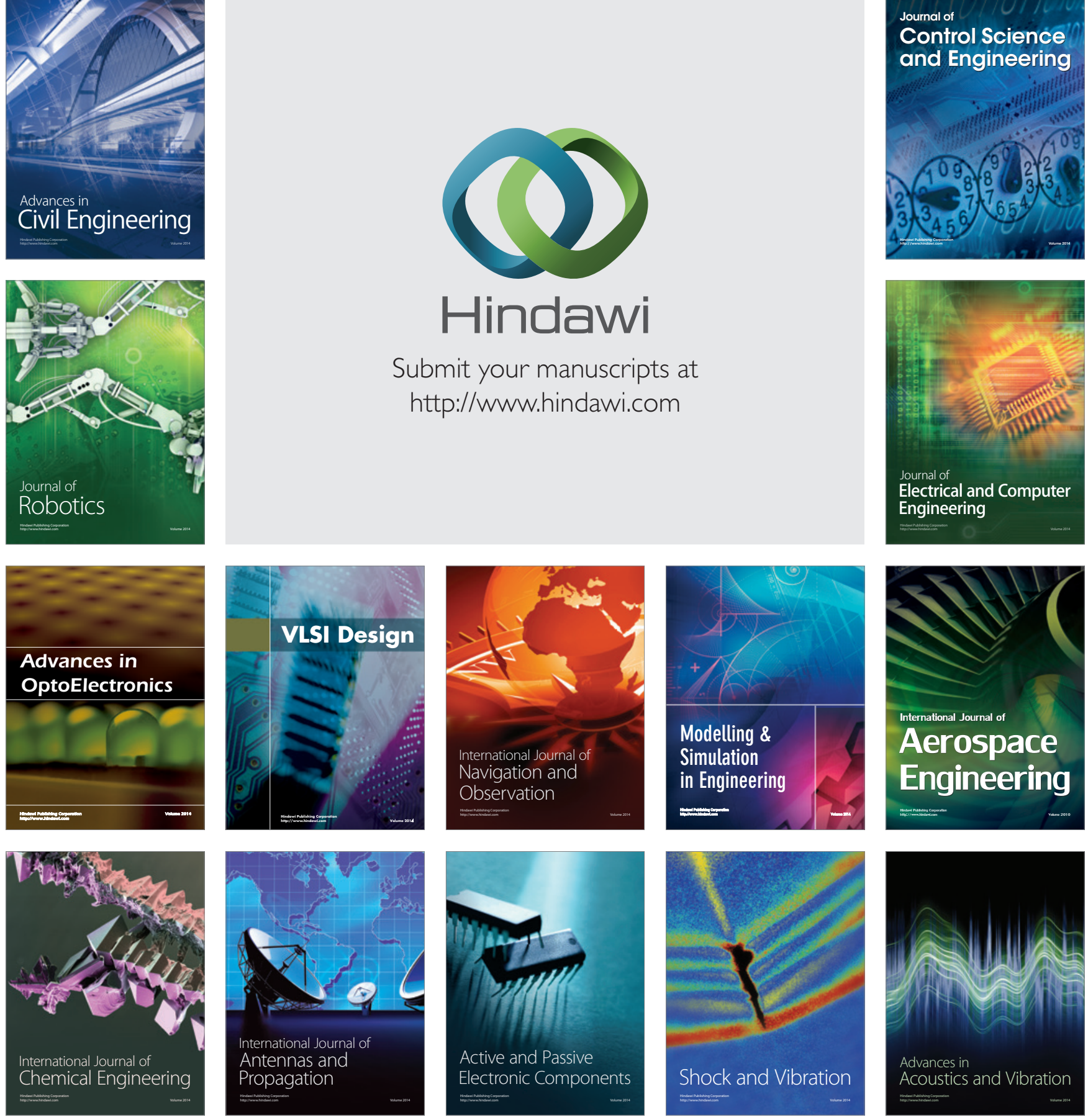